\title{
marges Marges
}

revue d'art contemporain Revue d'art contemporain

\section{$24 \mid 2017$}

L'expérience dans l'art

\section{« $32^{\mathrm{e}}$ Biennale de São Paulo. Incerta Viva »}

Foundation Biennale de São Paulo - 7 septembre - 11 décembre 2016

\section{Gabriel Ferreira Zacarias}

\section{(2) OpenEdition}

\section{Journals}

Édition électronique

URL : http://journals.openedition.org/marges/1290

DOI : $10.4000 /$ marges. 1290

ISSN : 2416-8742

Éditeur

Presses universitaires de Vincennes

\section{Édition imprimée}

Date de publication : 20 avril 2017

Pagination : 150-151

ISBN : 978-2-84292-574-1

ISSN : $1767-7114$

Référence électronique

Gabriel Ferreira Zacarias, " « 32e Biennale de São Paulo. Incerta Viva » », Marges [En ligne], 24 | 2017 , mis en ligne le 20 avril 2017, consulté le 25 septembre 2020. URL : http://journals.openedition.org/ marges/1290; DOI : https://doi.org/10.4000/marges.1290

Ce document a été généré automatiquement le 25 septembre 2020.

(C) Presses universitaires de Vincennes 


\title{
« $32^{\mathrm{e}}$ Biennale de São Paulo. Incerta Viva »
}

Foundation Biennale de São Paulo - 7 septembre - 11 décembre 2016

\author{
Gabriel Ferreira Zacarias
}

\section{RÉFÉRENCE}

« $32^{\mathrm{e}}$ Biennale de São Paulo. Incerta Viva » - Foundation Biennale de São Paulo - 7 septembre - 11 décembre 2016

$1 \quad$ La $32^{\mathrm{e}}$ édition de la Biennale de São Paulo a eu lieu du 7 septembre au 11 décembre 2016. Jochen Volz, le commissaire chargé de cette édition, a travaillé avec quatre commissaires adjoints : Gabi Ngcobo, Júlia Rebouças, Lars Bang Larsen et Sofía Olascoaga. Volz est déjà connu du public brésilien pour ses activités en tant que commissaire de l'Institut Inhotim - un musée d'art contemporain financé par un collectionneur privé qui a fait bâtir un grand parc au centre du pays pour héberger sa collection. Il est possible de percevoir des rapports entre le projet artistique de l'Institut Inhotim et celui de la $32^{\mathrm{e}}$ Biennale. Le bâtiment qui héberge traditionnellement l'exposition à São Paulo est également placé à l'intérieur d'un parc, le tout conçu par l'architecte Oscar Niemeyer. Les commissaires ont voulu mettre cela à profit, prévoyant des parcours de visite qui incorporent des promenades dans le parc, où l'on retrouve quelques œuvres d'artistes participant à l'événement. Depuis quelques éditions, l'entrée à la Biennale de São Paulo est gratuite, ce qui facilite la libre circulation entre le parc et l'exposition. La volonté de conduire les visiteurs du parc à visiter l'exposition se manifeste aussi par la disposition des œuvres à l'entrée. Au rezde-chaussée se trouvent des œuvres de grandes dimensions mais accessibles, comme Ágora : OcaTaperaTerreiro (2016), une cabane indigène construite par Bené Fonteles louant le syncrétisme religieux et la culture populaire ; ou encore les sculptures colorés de Frans Krajcberg, faites avec des troncs d'arbres et qui établissent un lien de continuité avec la végétation entourant le bâtiment. Cette insistance dans le rapport 
avec le parc environnant n'est pas une simple envie d'élargir l'espace d'exposition. Elle renforce la problématique écologique d'une exposition qui porte comme titre "Incerteza viva», soit "Incertitude vivante». Le commissaire explique dans le catalogue que le choix du thème lui est venu de la constatation que le marché éditorial est inondé par une marée de livres annonçant une catastrophe imminente. Néanmoins, le commissaire n'a pas voulu faire une exposition centrée sur la catastrophe, mais au contraire, il a voulu garder l'idée que l'art peut transformer le mauvais en bien. Selon lui, l'art serait apte à faire de ces menaces une source de création et de retrouver le vivant dans l'incertitude.

2 On voit ainsi que dès le départ le choix du commissaire ressort d'une ambiguïté. Si la menace de la catastrophe environnementale l'amène à parler d'écologie, il craint de formuler un discours trop sombre et veut garder espoir. Ce qu'il fait finalement, c'est réduire son rôle discursif. Il y a peu de dispositifs explicatifs au cours de l'exposition et aucune linéarité narrative n'est discernable. Il n'y a pas une ligne directrice qui oriente la disposition des œuvres. À la place du discours du commissaire, on trouve la parole des artistes qui, dans les audio-guides, commentent les œuvres de leurs pairs. Le dispositif est certes intéressant. Il nous reste néanmoins l'impression d'une exposition à certains égards décousue, dont les critères semblent parfois osciller. Tout en flirtant constamment avec le thème de la crise environnementale, les commissaires ne se décident pas nettement à affronter cette problématique. Le critère de l'incertitude reste ainsi trop vague et on a l'impression que tout peut y entrer. Au visiteur alors de parcourir l'exposition en quête des œuvres qui lui parlent. Comme toujours, il y a à prendre et à laisser et on y trouve, point positif, un bon nombre de jeunes artistes, d'origines assez variées. Un autre mérite de cette édition de la Biennale de São Paulo est de rester assez accessible au public en général et que l'absence d'un récit fermé laisse sans doute au visiteur une bonne marge de liberté. Mais ce retranchement discursif peut parfois être problématique, notamment là où la reprise d'œuvres du $20^{\mathrm{e}}$ siècle aurait bénéficié d'une mise en contexte - c'est le cas avec les travaux d'Öyvind Fahlström ou de Victor Grippo. Le travail de Grippo avait déjà été exposé à la Biennale de São Paulo en 1977 et rien n'est dit de cette remise-en-scène. L'œuvre Naturalizar al hombre, humanizar a la naturaleza, o Energía vegetal (1977), où l'artiste extrait de l'énergie électrique à partir de la putréfaction des pommes de terre, réapparaît comme purement liée à la thématique écologique, sans que le visiteur connaisse ses implications politiques d'origine - les électrodes renvoyant aux tortures commises par les gouvernements dictatoriaux de l'époque. L'absence de l'histoire dans le discours de l'exposition peut se comprendre par l'envie de rompre avec un modèle habituel d'exposition linéaire. Mais ce déni de l'histoire peut paraître inopportun, au moment même où le pays semble hanté à nouveau par son passé autoritaire. 